\title{
Multifunctional glass fiber/polyamide composites with thermal energy storage/release capability
}

\author{
G. Fredi, A. Dorigato*, A. Pegoretti \\ University of Trento, Department of Industrial Engineering and INSTM Research Unit Via Sommarive 9, 38123 Trento, Italy
}

Received 3 October 2017; accepted in revised form 29 November 2017

\begin{abstract}
Thermoplastic composite laminates with thermal energy storage (TES) capability were prepared by combining a glass fabric, a polyamide 12 (PA12) matrix and two different phase change materials (PCMs), i.e. a paraffinic wax microencapsulated in melamine-formaldehyde shells and a paraffin shape stabilized with carbon nanotubes. The melt flow index of the PA12/PCM blends decreased with the PCM concentration, especially in the systems with shape stabilized wax. Differential scanning calorimetry showed that, for the matrices with microcapsules, the values of enthalpy were approximately the $70 \%$ of the theoretical values, which was attributed to the fracture of some microcapsules. Nevertheless, most of the energy storage capability was preserved. On the other hand, much lower relative enthalpy values were measured on the composites with shape stabilized wax, due to a considerable paraffin leakage or degradation. The subsequent characterization of the glass fabric laminates highlighted that the fiber and void volume fractions were comparable for all the laminates except for that with the higher amount of shape stabilized wax, where the high viscosity of the matrix led to a low fiber volume fraction and higher void content. The mechanical properties of the laminates were only slightly impaired by PCM addition, while a more sensible drop of the elastic modulus, of the stress at break and of the interlaminar shear strength could be observed in the shape stabilized wax systems.
\end{abstract}

Keywords: polymer composites, polyamide 12, thermal energy storage, phase change materials, multifunctional composites

\section{Introduction}

The growing increase in greenhouse gases emissions and high cost of fossil fuel are the main reasons for the need of a more effective use of energy in all the domestic and industrial activities. Thermal energy storage (TES) consists in storing heat for a later use thus reducing the discrepancy between energy availability and demand with beneficial effects on thermal management processes [1-3]. TES systems currently find employment in many applications, such as in power generation systems $[4,5]$ and in construction $[6,7]$, applications where the need for thermal energy is considerable and varies noticeably on a daily and seasonal basis [8].

Thermal energy can be stored and released as sensible heat, through a thermochemical reaction, or as latent heat by using phase change materials (PCMs). These materials generally undergo reversible solid/ solid or solid/liquid phase transitions and can be classified as organic, inorganic or eutectic [1]. PCMs can accumulate a large amount of thermal energy per unit mass, at a nearly constant temperature, with a low change in volume [9]. Organic PCMs, and paraffin waxes in particular, are the most widely used materials for TES applications $[1,10,11]$. They present considerable advantages over other PCMs, such as high energy density, small volume change over phase transition, narrow working temperature range, tunable operating temperature, low density and cheapness $[12,13]$. On the other hand, organic PCMs have some drawbacks, such as low thermal conductivity and need for confinement to avoid leakage above the 
melting temperature [14]. The leakage issue can be tackled in two main ways. The first is the encapsulation of the PCMs in organic or inorganic micro- or nano shells, which also protect the PCM from the external environment and may increase its thermal stability [15-17]. The second method is called 'shape stabilization', and involves the confinement of the PCM using a polymer matrix [18-21], a porous or layered material [22,23] or an inorganic nanofiller [24-26]. If the shape stabilization is performed with a metallic or a carbon based material, this also leads to an increase of the overall thermal conductivity $[27,28]$.

TES systems based on PCMs find applications in buildings [29, 30], hot/cold water storage [31], solar thermal power plants [32], smart thermoregulating textiles [25, 33], and thermal management of electronic devices [22]. In most of these applications, the TES function is performed by a dedicated added module, containing PCMs. However, there are some fields where the addition of a new part performing the thermal management would lead to an unacceptable increase in mass and volume. In these cases, it would be advantageous to have a multifunctional structure that also contributes to the thermal management.

The most suitable materials that can be designed as multifunctional are the composite materials [34-36]. Being composed of two or more phases with different properties [37, 38], they could be designed to combine load bearing properties and functional capabilities. Particularly, lightweight polymer matrix composites performing TES functions and a structural/semi structural role could be usefully employed in fields where weight and volume savings are crucial design parameters but the temperature control is also important. Examples of such fields can be the automotive, aerospace, portable electronics and technical garments industries. However, even though there are many examples in the literature of encapsulated and shape stabilized PCMs embedded in a polymer matrix [5, 12, 17, 29, 39-42], only few papers can be found that deal with the development of polymer composites merging structural and TES functions. Most of the examples of such composites regard sandwich structures that have functions of thermal management with [22] or without [43, 44] the use of a PCM. More recently, Yoo and coworkers [45, 46] developed a glass fiber/epoxy composite including a commercial microencapsulated PCM and characterized its thermal [45], mechanical and viscoelastic [46] properties. Moreover, our group is currently preparing and characterizing multifunctional epoxy/ carbon fiber composites containing various percentages of a paraffin shape stabilized with carbon nanotubes (CNTs) [47].

In a polymer composite, the matrix can be a thermoplastic or a thermosetting polymer. Thermoplastic composites reinforced with long and short fibers (fiber reinforced thermoplastics, FRTs) are attracting increasing attention because of their advantages over their thermosetting counterpart. They provide higher toughness, higher strain to failure, superior impact resistance and high fracture resistance, which impart outstanding damage tolerance properties [48]. Moreover, thermoplastics have unlimited shelf life at room temperature, lower cost and shorter fabrication time, since they do not have to be cured. They can be easily reprocessed, post thermoformed, joined and repaired by welding or solvent bonding [48-50]. Because of all these features, thermoplastic composites are widely employed in many fields, such as the transportation industry, where they are used to realize structural/semi structural parts like bumpers, front end modules and dashboard frames [51, 52]. Among all the FRTs, those having a polyamide (PA) based matrix and a long (continuous or discontinuous) fiber reinforcement are the most widely used today, thanks to their high mechanical properties and relatively low cost [52].

To the best of our knowledge, no papers dealing with the development of structural thermoplastic composites with TES capability can be found in the open scientific literature, since the small number of research works on multifunctional structural composites with TES properties focus on composites with a thermosetting matrix. On the basis of these considerations, the objective of the present work is to develop and characterize multifunctional composite laminates based on polyamide 12 (PA12) and an Eglass fabric, in which the TES function is achieved by adding two different paraffinic PCMs, able to store and release latent heat in the temperature range 40 $50^{\circ} \mathrm{C}$. The aim and the novelty of this work is to produce new composite materials able to exploit all the aforementioned advantages of thermoplastic composites, as well as combine good mechanical properties and thermal energy storage/release capability. PA12 was chosen as a matrix because, due to a relatively high methylene/amide ratio (11/1), it presents a lower moisture sensitivity and a lower melting temperature than the more common PA6 and PA66 
[53-55]. Additionally, there are many examples in the literature of PA12 reinforced with continuous and discontinuous glass fibers [49, 56-59]. PA12 was blended with two selected PCMs, namely (1) a commercial microencapsulated PCM, in which the paraffinic core is embedded in melamine-formaldehyde shells; and (2) a shape stabilized PCM, where the leakage of paraffin above the melting temperature is prevented by the presence of CNTs. The most promising PA12/PCM compositions were then chosen to prepare composite laminates through the addition of a glass fiber fabric. The resulting laminates were thermally and mechanically characterized, and the properties were then correlated to their microstructure.

\section{Experimental}

\subsection{Materials}

Two paraffinic PCMs were considered, namely a microencapsulated one and a shape stabilized one. Since one of the main goals of this work was to compare a system with microencapsulated paraffin with a system with shape stabilized paraffin, two paraffin waxes with approximately the same melting/crystallization temperatures and enthalpies were selected.

The utilized microencapsulated PCM was the Microtek MPCM43D, provided by Microtek Laboratories Inc. (Dayton, OH, USA). In this system, the PCM phase, i.e. a paraffin wax, had a melting temperature of $43^{\circ} \mathrm{C}$ and it was encapsulated inside a stable melamine-formaldehyde based shell, which constitutes the $10-15 \%$ of the mass. These microcapsules were characterized by a mean diameter of $17-20 \mu \mathrm{m}$, and the melting enthalpy declared by the producer was $190-200 \mathrm{~J} / \mathrm{g}$.

The shape stabilized PCM was made by mixing a paraffin wax with carbon nanotubes, following the approach recently reported in [47]. RT44HC paraffin wax (melting temperature $=44^{\circ} \mathrm{C}$, melting enthalpy $=$ $240 \mathrm{~J} / \mathrm{g}$ ) was supplied by Rubitherm Technologies GmbH (Berlin, Germany). Multi-walled carbon nanotubes $\mathrm{NC} 7000^{\circledR}$ (average diameter $9.5 \mathrm{~nm}$, average length $1.5 \mu \mathrm{m}$, BET surface area $250-300 \mathrm{~m}^{2} / \mathrm{g}$ ) were purchased from Nanocyl SA (Sambreville, Belgium).

The thermoplastic matrix was a Rilsan ${ }^{\circledR}$ PA12, supplied by Arkema Group (Lyon, France) in form of polymer chips (density $1.01 \mathrm{~g} / \mathrm{cm}^{3}$, melting temperature $174^{\circ} \mathrm{C}$ ).

The glass fiber (GF) fabric was a bi-directional crimped roving fabric made of E-glass fibers (fiber diameter $12 \mu \mathrm{m}$ ), supplied by Angeloni Srl (Venice, Italy). All the materials were used as received.

\subsection{Sample preparation}

\subsubsection{Preparation of PA12/PCM blends}

The microencapsulated system was ready to use as received, while the shape stabilized PCM was prepared as described in reference [47] and briefly reported here. CNTs were added to the molten paraffin in a weight ratio of 15:85 and vigorously mixed for 5 minutes at $500 \mathrm{rpm}$ at $80^{\circ} \mathrm{C}$ with a Dispermat mechanical mixer. As reported in our previous work, this specific CNT weight fraction was chosen because it guaranteed an optimal shape stabilization with no leakage above the melting temperature of the paraffin [47]. The mixture was then cooled down to room temperature and grinded in a cryogenic blade miller Ika Laborteknik M20, to obtain a fine powder denoted as ParCNT in the text.

The PA12/PCM blends were prepared by melt compounding and hot pressing. PA12 granules and the PCMs (either the microcapsules or the ParCNT powder) were melt compounded in a Thermo Haake Rheomix 600 internal mixer, equipped with counterrotating rotors, at different PCM concentrations (ranging from 15 to $60 \mathrm{wt} \%$ ). The materials were mixed at $200^{\circ} \mathrm{C}$ at $60 \mathrm{rpm}$ for 5 minutes. The resulting compounds were molded through a Carver hot-plate press at $200^{\circ} \mathrm{C}$ for 5 minutes under an applied pressure of $1.75 \mathrm{MPa}$. In this way, neat PA12 and PA12/PCM blends at different concentrations were obtained in form of square sheets of $120 \times 120 \mathrm{~mm}^{2}$, with a thickness of approximately $2 \mathrm{~mm}$. The prepared matrices are listed in Table 1. The neat PA12 was called PA12-N, the blends with capsules were designed as PA12-Cx and the blends with ParCNT were denoted as PA12-Px $(\mathrm{x}=15,30,45,60)$.

Table 1. list of the prepared matrices

\begin{tabular}{|l|c|c|c|c|}
\hline \multicolumn{1}{|c|}{ Sample } & $\begin{array}{c}\text { PA12 } \\
{[\mathbf{w t} \%]}\end{array}$ & $\begin{array}{c}\text { Paraffin } \\
\text { RT44HC } \\
{[\mathbf{w t} \%]}\end{array}$ & $\begin{array}{c}\text { CNTs } \\
{[\mathbf{w t} \%]}\end{array}$ & $\begin{array}{c}\text { Microcapsules } \\
\text { M43D } \\
{[\mathbf{w t} \%]}\end{array}$ \\
\hline PA12-N & 100 & - & - & - \\
\hline PA12-C15 & 85 & - & - & 15 \\
\hline PA12-C30 & 70 & - & - & 30 \\
\hline PA12-C45 & 55 & - & - & 45 \\
\hline PA12-C60 & 40 & - & - & 60 \\
\hline PA12-P15 & 85 & 12.8 & 2.2 & - \\
\hline PA12-P30 & 70 & 25.5 & 4.5 & - \\
\hline PA12-P45 & 55 & 38.3 & 6.7 & - \\
\hline PA12-P60 & 40 & 51.0 & 9.0 & - \\
\hline
\end{tabular}




\subsubsection{Preparation of the PA12/PCM-GF laminates}

The prepared PA12/PCM blends were used to fabricate composite laminates with E-glass fiber fabric. Five matrix compositions were chosen, namely PA12-N, PA12-C30, PA12-C60, PA12-P30 and PA12-P60. PA12/PCM sheets were prepared through melt compounding and hot-plate pressing, in the way described in Section 2.2.1. These sheets had a smaller thickness than those described before, of approximately $0.3 \mathrm{~mm}$, to ease the process of lamination. They were alternated to the glass fiber fabric to prepare laminates consisting of 5 laminae with surface dimensions of $120 \times 120 \mathrm{~mm}^{2}$, via hot pressing at $200^{\circ} \mathrm{C}$ for 5 minutes under an applied pressure of 3.4 MPa. The resulting laminates had a thickness of approximately $2 \mathrm{~mm}$. The laminates were designated as GF-N, GF-C30, GF-C60, GF-P30 and GF-P60.

\subsection{Experimental techniques}

\subsubsection{Characterization of the matrices}

Melt flow index (MFI) tests at $230{ }^{\circ} \mathrm{C}$ and with a weight of $2.16 \mathrm{~kg}$ were performed on all the prepared matrices with a Dynisco LMI D4000 machine.

The density of the matrices was measured with a helium pycnometer Micrometrics AccuPyc 1330TC, at $23^{\circ} \mathrm{C}$. In order to reach stationary conditions, the density of each sample was the average of 99 consecutive measures.

Scanning electron microscopy (SEM) images of the cryofractured surfaces of all the matrices were acquired through a Jeol IT300 scanning electron microscope at an accelerating voltage of $10 \mathrm{kV}$, after Pt-Pd sputtering.

Differential scanning calorimetry (DSC) was performed with a Mettler DSC30 machine under a nitrogen flow of $150 \mathrm{~mL} / \mathrm{min}$, in a temperature range between 0 and $230^{\circ} \mathrm{C}$, at a heating/cooling rate of $10^{\circ} \mathrm{C} / \mathrm{min}$. All the specimens had a mass of approximately $15 \mathrm{mg}$ and were subjected to a first heating scan, a cooling scan and a second heating scan. In this way, melting/crystallization temperatures $\left(T_{\mathrm{m}}\right.$, $\left.T_{\mathrm{c}}\right)$, and melting/crystallization enthalpies $\left(\Delta H_{\mathrm{m}}, \Delta H_{\mathrm{c}}\right)$ of the PCMs were determined. Moreover, relative melting/crystallization enthalpies $\left(\Delta H_{\mathrm{m}}^{\mathrm{rel}}, \Delta H_{\mathrm{c}}^{\mathrm{rel}}\right)$ were obtained by dividing the $\Delta H_{\mathrm{m}}$ and $\Delta H_{\mathrm{c}}$ values for the melting/crystallization enthalpy of the capsules or the ParCNT powder, considering the nominal PCM content in the blends. The melting and crystallization temperatures and enthalpies of the PA12 $\left(T_{\mathrm{m}}^{\mathrm{PA}}, T_{\mathrm{c}}^{\mathrm{PA}}\right.$, $\left.\Delta H_{\mathrm{m}}^{\mathrm{PA}}, \Delta H_{\mathrm{c}}^{\mathrm{PA}}\right)$ were also recorded.

Thermogravimetric analysis (TGA) was carried out by using a Mettler TG 50 machine under a nitrogen flow of $200 \mathrm{~mL} / \mathrm{min}$, in a temperature interval between 30 and $700^{\circ} \mathrm{C}$, at a heating rate of $10^{\circ} \mathrm{C} / \mathrm{min}$. The test allowed the determination of the temperatures associated to a mass loss of the $1 \%\left(T_{1 \%}\right)$, of the $5 \%\left(T_{5 \%}\right)$, and the decomposition temperature $\left(T_{\mathrm{d}}\right)$, taken as the temperature associated to the maximum mass loss rate.

To evaluate the dimensional stability of the resulting matrices, Vicat tests were performed according to ASTM D 1525 standard at a heating rate of $120^{\circ} \mathrm{C} / \mathrm{h}$ and under an applied load of $10 \mathrm{~N}$, in a silicone oil bath. The nominal dimensions of the samples were $10 \times 10 \times 5 \mathrm{~mm}^{3}$.

Quasi-static tensile tests were performed according to the ASTM D638-10 standard, with a universal testing machine Instron 4502, equipped with a $1 \mathrm{kN}$ load cell. Dumbbell 1BA specimens (standard UNI EN ISO 527-2) were cut by means of a specimen cutter Ceast 6051. The dimensions of the specimens were the following: length of the narrow parallel sided portion $=30 \pm 0.5 \mathrm{~mm}$, width of the narrow portion $=5 \pm 0.5 \mathrm{~mm}$, thickness $\geq 2 \mathrm{~mm}$, gauge length $=$ $25 \pm 0.5 \mathrm{~mm}$. For each composition, five specimens were tested at $0.25 \mathrm{~mm} / \mathrm{min}$ for the measurement of the elastic modulus, using a resistance extensometer Instron 2620 with a gauge length of $12.5 \mathrm{~mm}$. The elastic modulus $(E)$ was measured as the secant modulus on the stress-strain curve between strain values of 0.05 and $0.25 \%$. Five additional specimens were tested until failure, at a crosshead speed of $10 \mathrm{~mm} / \mathrm{min}$. The stress and strain at the yield point $\left(\sigma_{\mathrm{y}}, \varepsilon_{\mathrm{y}}\right)$ and at break $\left(\sigma_{\mathrm{B}}, \varepsilon_{\mathrm{B}}\right)$ were thus determined.

\subsubsection{Characterization of the laminates}

Optical microscope observations of the composites were made with a Leica DM6000M optical microscope. The samples were englobed, lapped and observed to investigate the disposition of the fibers and the distribution of the components in the matrices. The density of the laminates was measured with a He pycnometer Micrometrics AccuPyc 1330TC at $23^{\circ} \mathrm{C}$. The density of each sample was the average of 99 measures. The density of neat glass fibers was also measured.

DSC and TGA tests were performed in the same experimental conditions utilized for the matrices (see 
Section 2.3.1). These tests were carried out also on the neat glass fibers. TGA measurements allowed the calculation of an experimental weight fraction of fibers $\left(\omega_{\mathrm{f}}\right)$, from which a theoretical density of the laminates was computed. By a comparison with the experimental density obtained via pycnometer measures, the volume fraction of voids $\left(\varphi_{\mathrm{v}}\right)$ was calculated. Then, the volume fraction of the fibers $\left(\varphi_{f}\right)$ and the matrix $\left(\varphi_{\mathrm{m}}\right)$ could be computed.

Quasi-static tensile tests were performed on the laminates, according to the ASTM D3039 standard. Tests were performed with a universal testing machine Instron 4502 equipped with a $10 \mathrm{kN}$ load cell. Rectangular specimens with surface dimensions of $100 \times 10 \mathrm{~mm}^{2}$ (and the thickness of the laminate) were cut from each laminate with a diamond wheel. The specimens were tabbed at both ends with glass fiber composite tabs, to avoid damages in the gripping zone. In this way, the elastic modulus $(E)$ and the tensile properties at break $\left(\sigma_{\mathrm{B}}, \varepsilon_{\mathrm{B}}\right)$ of the laminates were determined.

Short beam shear tests were carried out according to the ASTM D 2344 standard, to evaluate the interlaminar shear strength of the prepared laminates. The tested specimens were cut out of the prepared laminates with a diamond wheel and had nominal dimensions of $15 \times 5 \times 2 \mathrm{~mm}^{3}$. Tests were performed using an Instron 5969 universal testing machine, equipped with a $50 \mathrm{kN}$ load cell. The span length was fixed at $8 \mathrm{~mm}$ and the crosshead speed was fixed at $1 \mathrm{~mm} / \mathrm{min}$. The interlaminar shear strength (ILSS) was calculated with the Equation (1):

$I L S S=\frac{3}{4} \frac{P_{\mathrm{m}}}{b \cdot h}$

where $P_{\mathrm{m}}$ is the maximum load observed during the test and $b$ and $h$ are the specimen width and thickness, respectively. At least five specimens were tested for each sample.

\section{Results and discussion}

\subsection{Characterization of the matrices}

Table 2 reports the results of the MFI tests on the matrices. For the matrices with microcapsules, as the capsule content increases the MFI decreases, reaching a minimum of $5.2 \mathrm{~g} / 10 \mathrm{~min}$ for the PA12-C60 sample. Also for the matrices with CNT-stabilized paraffin, the MFI decreases with an increase of ParCNT, but in a more dramatic way. Compared to the MFI value of the neat PA12, the MFI is halved with a ParCNT
Table 2. Results of MFI tests on the prepared matrices

\begin{tabular}{|l|c|c|c|}
\hline \multicolumn{1}{|c|}{ Sample } & $\begin{array}{c}\text { Load } \\
{[\mathbf{k g}]}\end{array}$ & $\begin{array}{c}\boldsymbol{T} \\
{\left[{ }^{\circ} \mathbf{C}\right]}\end{array}$ & $\begin{array}{c}\text { MFI } \\
{[\mathbf{g} / \mathbf{1 0} \mathbf{~ m i n}]}\end{array}$ \\
\hline PA12-N & 2.16 & 230 & $10.3 \pm 0.6$ \\
\hline PA12-C15 & 2.16 & 230 & $9.2 \pm 0.3$ \\
\hline PA12-C30 & 2.16 & 230 & $6.9 \pm 0.6$ \\
\hline PA12-C45 & 2.16 & 230 & $6.1 \pm 0.6$ \\
\hline PA12-C60 & 2.16 & 230 & $5.2 \pm 0.6$ \\
\hline PA12-P15 & 2.16 & 230 & $5.2 \pm 0.8$ \\
\hline PA12-P30 & 2.16 & 230 & $0.7 \pm 0.1$ \\
\hline PA12-P45 & 5.00 & 230 & $0.7 \pm 0.1$ \\
\hline PA12-P60 & 10.00 & 230 & $0.5 \pm 0.1$ \\
\hline
\end{tabular}

content of only $15 \mathrm{wt} \%$ and is close to $0.7 \mathrm{~g} / 10 \mathrm{~min}$ for a ParCNT content of $30 \mathrm{wt} \%$. Further increases of the ParCNT concentration decrease the fluidity in such a way that the measures could not be performed with a mass of $2.16 \mathrm{~kg}$, but a heavier weight had to be used to obtain a reliable MFI result (see Table 2). This is probably due to the increasing CNT content, since these nanofillers are well known to heavily increase the viscosity of molten polymers. Because of the change in the applied load, it is not possible to draw a trend of the MFI, but these results suggest that it may be difficult to obtain a composite without pores at elevated ParCNT contents. This also implies that, although both PCMs types decrease the fluidity of the PA12, the effect of the capsules is less intense than that of the ParCNT, which indicates a better processability of this PCM during the fabrication of laminates.

Figure 1 shows the SEM micrographs of some prepared matrices, namely PA12-C15, PA12-C60, PA12-P15 and PA12-P60, taken at the same magnification $(1000 \times)$. For each system, only the SEM images of the matrices with the lower and the higher PCM content (15 and 60\%) are reported, for the sake of brevity. In the PA12-C15 and PA12-C60 samples (Figure 1a, 1b), capsules with dimensions ranging from 5 to $20 \mu \mathrm{m}$ can be observed, and a good adhesion between PA12 and the melamine-formaldehyde shells can be detected. Some capsules are broken, which can be due to the production process or to the cryofracture operations. No microcapsule agglomerates are visible, and the uniform distribution of the capsules determines a morphological continuity of the matrix, which is important for the mechanical performance of the blends. In the sample with $15 \%$ of ParCNT (Figure 1c), small domains of ParCNT are visible, but the interfacial adhesion is poorer than 


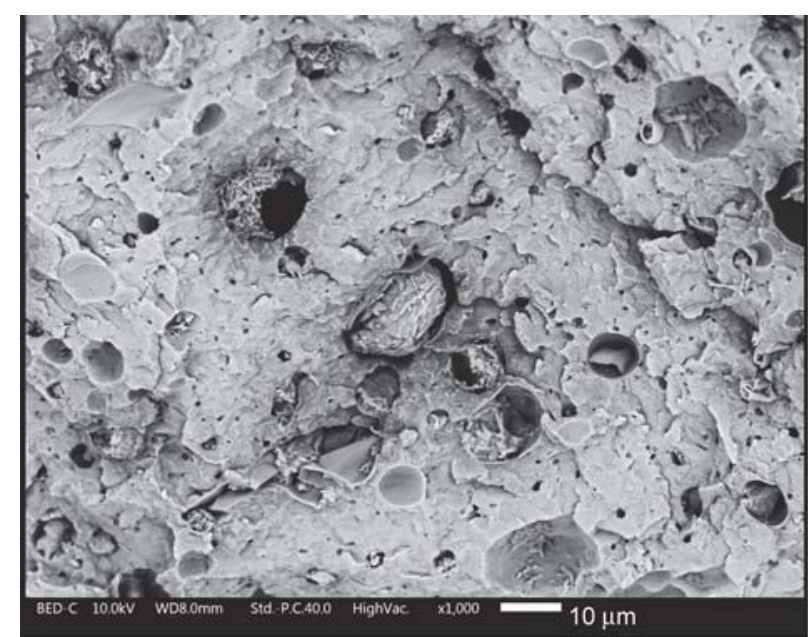

a)

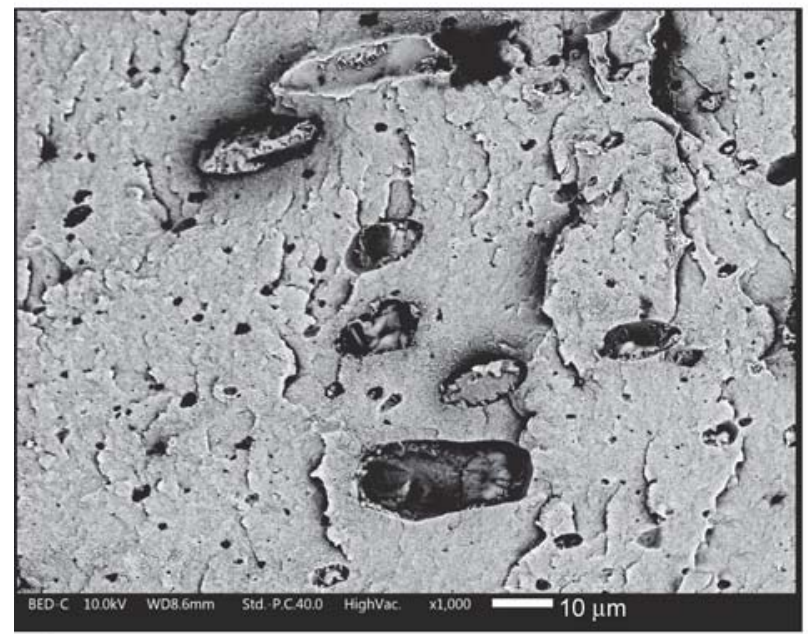

c)

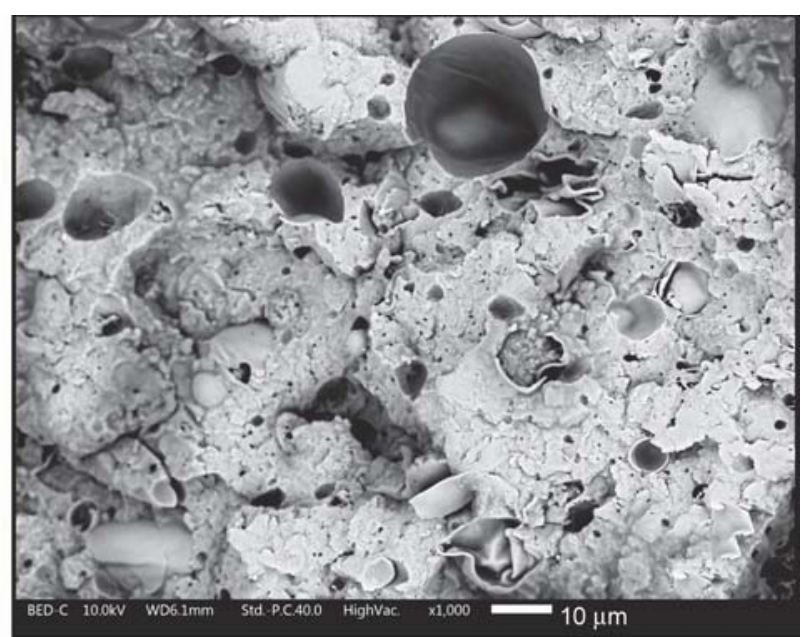

b)

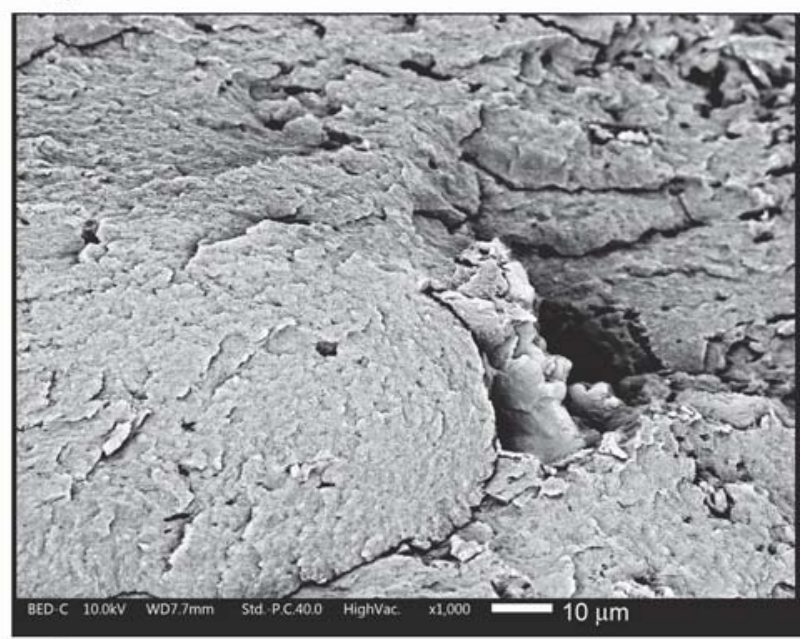

d)

Figure 1. SEM micrographs of the cryofractured surface of some of the prepared matrices. (a) PA12-C15; (b) PA12-C60; (c) PA12-P15; (d) PA12-P60.

that observed with capsules. Conversely, the PCM domains are not visible in the PA12-P60 sample (Figure 1d). A non uniform distribution of the ParCNT was observed in the micrographs of other specimens with the same composition, with the presence of large $(500 \mu \mathrm{m})$ domains. Also in this case, the results suggest that it could be easier to process the matrices with capsules than those blended with ParCNT powder.

Figure 2 shows the DSC thermograms relative to the first heating scan of the matrices with capsules and with ParCNT, respectively. The most important DSC results are summarized in Table 3. The data of the second heating scan are not reported for the sake of brevity, as no important differences were detected between the first and the second heating scan. For the sample PA12-N, an endothermic melting peak can be observed in the heating scan at approximately $180^{\circ} \mathrm{C}$. The same peak is visible also for the other samples, where an additional endothermic peak is visible at approximately $40-50^{\circ} \mathrm{C}$. This last peak is associated to the melting of the PCM, either in the capsules (Figure 2a) or in the ParCNT (Figure 2b) blends. Corresponding crystallization peaks have been observed in the cooling scans (not reported here for the sake of brevity). For the matrices with capsules, the melting enthalpy of the PCM increases with an increase of capsules content, and the relative developed enthalpy is approximately $70 \%$ of the expected one, according to the nominal capsules content. These values of relative melting and crystallization enthalpy of the PCMs are comparable with those observed in the literature for blends with paraffin microcapsules embedded in a thermoplastic polymeric matrix [60, 61]. This suggests that, during the processing steps, some capsules were broken, and the paraffin leaked out of the blend. Nevertheless, most of the thermal energy storage/release capability is retained. Conversely, for matrices with ParCNT (Figure 2b), the PCM melting enthalpy does not follow a trend with the ParCNT content and enthalpy values are in the 

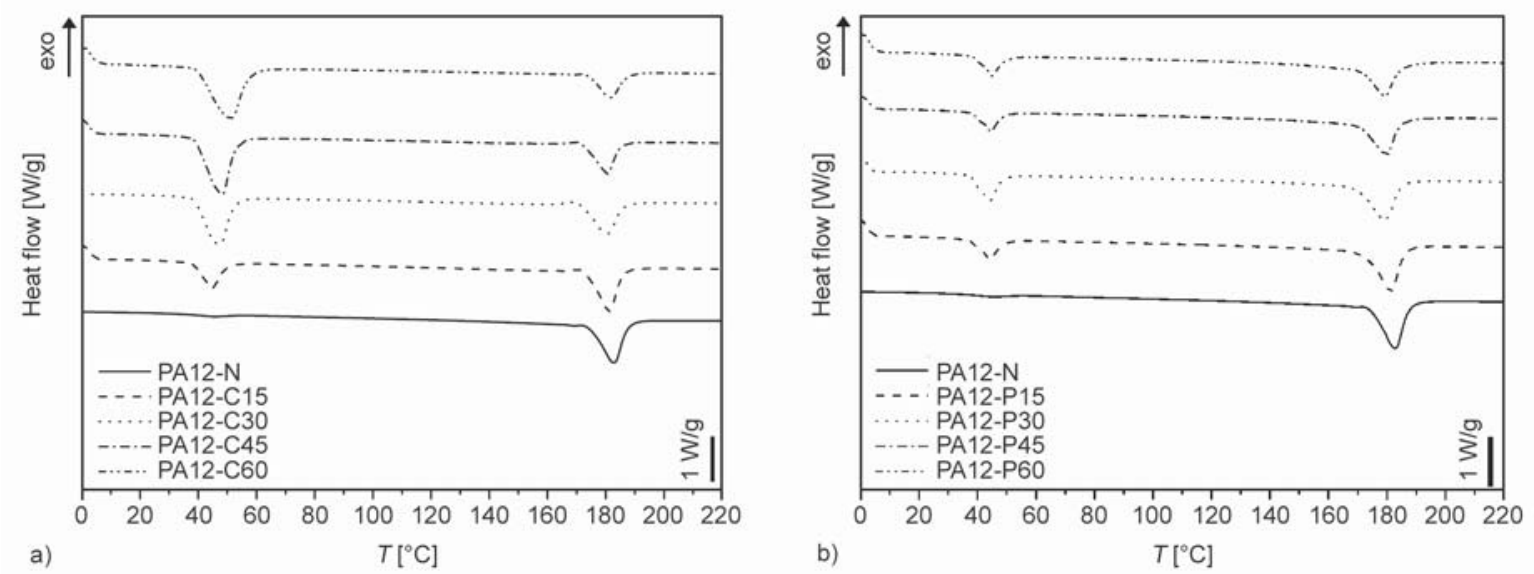

Figure 2. DSC thermograms of the prepared matrices. (a) Matrices with microcapsules; (b) matrices with paraffin and CNTs.

Table 3. Results of the DSC tests on the prepared matrices

\begin{tabular}{|l|c|c|c|c|c|c|c|c|c|}
\hline \multicolumn{1}{|c|}{ Sample } & $\begin{array}{c}\boldsymbol{T}_{\mathbf{m}} \\
{\left[{ }^{\circ} \mathbf{C}\right]}\end{array}$ & $\begin{array}{c}\Delta \boldsymbol{H}_{\mathbf{m}} \\
{[\mathbf{J} / \mathbf{g}]}\end{array}$ & $\begin{array}{c}\Delta \boldsymbol{H}_{\mathbf{m}}^{\text {rel }} \\
{\left[\mathbf{\%}^{\text {rol }}\right.}\end{array}$ & $\begin{array}{c}\boldsymbol{T}_{\mathbf{m}}^{\mathbf{P A}} \\
{\left[{ }^{\circ} \mathbf{C}\right]}\end{array}$ & $\begin{array}{c}\Delta \boldsymbol{H}_{\mathbf{m}}^{\mathbf{P A}} \\
{[\mathbf{J} / \mathbf{g}]}\end{array}$ & $\begin{array}{c}\boldsymbol{T}_{\mathbf{c}} \\
{\left[{ }^{\circ} \mathbf{C}\right]}\end{array}$ & $\begin{array}{c}\Delta \boldsymbol{H}_{\mathbf{c}} \\
{[\mathbf{J} / \mathbf{g}]}\end{array}$ & $\begin{array}{c}\boldsymbol{T}_{\mathbf{c}}^{\mathbf{P A}} \\
{\left[{ }^{\circ} \mathbf{C}\right]}\end{array}$ & $\begin{array}{c}\Delta \boldsymbol{H}_{\mathbf{c}}^{\mathbf{P A}} \\
{[\mathbf{J} / \mathbf{g}]}\end{array}$ \\
\hline PA12-N & - & - & - & 181.2 & 47.9 & - & - & 155.7 & 52.0 \\
\hline PA12-C15 & 43.9 & 20.5 & 68.3 & 179.8 & 40.9 & 32.4 & 18.1 & 153.2 & 40.8 \\
\hline PA12-C30 & 45.9 & 46.8 & 77.9 & 179.3 & 35.6 & 23.0 & 46.8 & 152.0 & 36.0 \\
\hline PA12-C45 & 46.2 & 61.2 & 67.9 & 172.2 & 31.0 & 24.7 & 61.2 & 155.7 & 31.1 \\
\hline PA12-C60 & 49.1 & 76.2 & 63.8 & 180.2 & 25.9 & 21.8 & 71.7 & 152.6 & 23.8 \\
\hline PA12-P15 & 43.3 & 16.1 & 57.3 & 172.2 & 46.6 & 33.2 & 11.3 & 160.5 & 46.3 \\
\hline PA12-P30 & 43.1 & 21.1 & 37.6 & 177.7 & 42.6 & 32.6 & 15.6 & 165.4 & 42.8 \\
\hline PA12-P45 & 43.5 & 14.0 & 16.7 & 178.4 & 42.8 & 29.2 & 8.6 & 158.7 & 41.3 \\
\hline PA12-P60 & 44.0 & 16.4 & 14.6 & 178.0 & 46.4 & 30.4 & 12.2 & 160.7 & 46.1 \\
\hline
\end{tabular}

$T_{\mathrm{m}} \quad$ melting temperature of the $\mathrm{PCM}\left[{ }^{\circ} \mathrm{C}\right]$

$\Delta H_{\mathrm{m}} \quad$ PCM melting enthalpy $[\mathrm{J} / \mathrm{g}]$

$\Delta H_{\mathrm{m}}^{\text {rel }} \quad$ relative PCM melting enthalpy [\%]

$T_{\mathrm{m}}^{\mathrm{PA}} \quad$ melting temperature of PA $12\left[{ }^{\circ} \mathrm{C}\right]$

$\Delta H_{\mathrm{m}}^{\mathrm{PA}} \quad$ melting enthalpy of PA $12[\mathrm{~J} / \mathrm{g}]$

$T_{\mathrm{c}} \quad$ crystallization temperature of the $\mathrm{PCM}\left[{ }^{\circ} \mathrm{C}\right]$

$\Delta H_{\mathrm{c}} \quad$ PCM crystallization enthalpy $[\mathrm{J} / \mathrm{g}]$

$T_{\mathrm{c}}^{\mathrm{PA}} \quad$ crystallization temperature of PA $12\left[{ }^{\circ} \mathrm{C}\right]$

$\Delta H_{\mathrm{c}}^{\mathrm{PA}} \quad$ crystallization enthalpy of PA12 [J/g]

range 14-21 J/g, well below the expected values (see Table 3). This suggests that most of the paraffin was degraded or leaked out of the matrix during the production process. Interestingly, the crystallization temperature of PA12 matrix is increased of about $5^{\circ} \mathrm{C}$ in the ParCNT based blends. As already observed in our previous papers on polyamide 6-clay nanocomposites [62], this is probably due to the nucleating effect played by CNTs within the matrix.

The paraffin leakage/degradation effect is visible also in the TGA results, reported in Figure 3 and in Table 4 . The residual mass and the mass loss derivative of the systems with capsules as a function of temperature are reported in Figure 3a, 3b. As the capsule content increases, the curves shift to lower temperatures and the values of $T_{1 \%}$ and $T_{5 \%}$ decrease, thus indicating a lower thermal resistance. This was expected, since the degradation temperature of the neat PA12 is higher than that of the PCM capsules. The blends show two distinct degradation steps; the first is associated to the degradation of the capsules and proportional to the capsules content $\left(300-400^{\circ} \mathrm{C}\right)$, and the second is related to the degradation of the PA12 (450$\left.500^{\circ} \mathrm{C}\right)$. The TGA thermograms of the blends with paraffin are reported in Figure 3c, 3d. The ParCNT powder presents a degradation peak temperature $T_{\mathrm{d}}$ of approximately $210^{\circ} \mathrm{C}$, well below that of the capsules. Considering that the PCM concentration within the capsules is not different from the paraffin content in the CNT stabilized systems, it can be concluded that the PCM encapsulation delays the degradation of the PCM and improves the overall thermal resistance, while CNTs do not perform any thermal barrier effect. This implies that the capsules are more suitable 

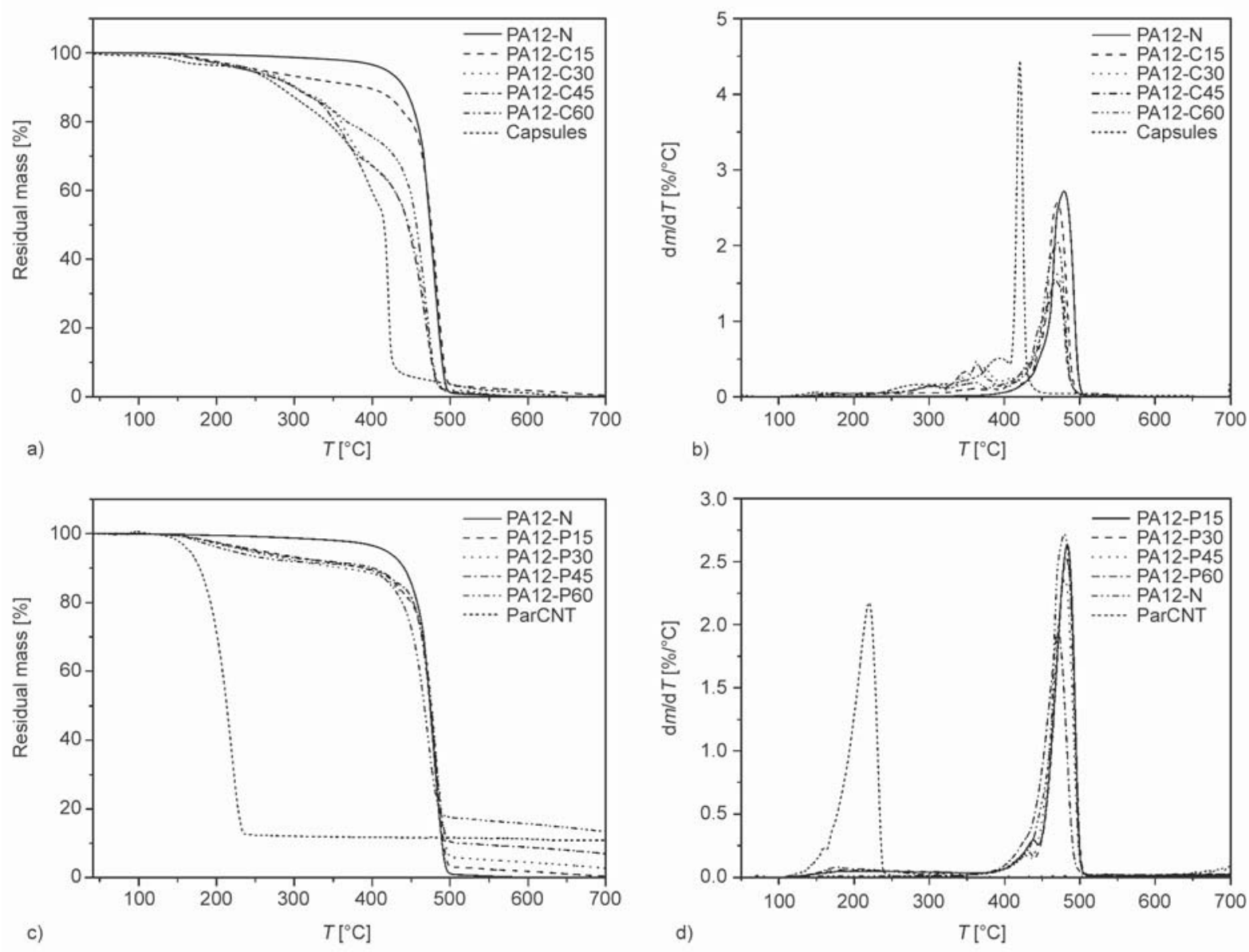

Figure 3. TGA thermograms of the prepared matrices. (a) Matrices with microcapsules, residual mass; (b) matrices with microcapsules, derivative of the mass loss; (c) matrices with paraffin and CNTs, residual mass; (d) derivative of the mass loss.

as PCM coupled with a polymer system as PA12, which has to be processed at a temperature around $200^{\circ} \mathrm{C}$. Also for the systems with ParCNT, the blends show a first degradation step in correspondence of the degradation of the PCM, and a second one where the PA12 degrades, but the mass loss associated to

Table 4. Results of the TGA tests on the prepared matrices

\begin{tabular}{|l|c|c|c|}
\hline \multicolumn{1}{|c|}{ Sample } & $\begin{array}{c}\mathbf{T}_{\mathbf{1} \%} \\
{\left[{ }^{\circ} \mathbf{C}\right]}\end{array}$ & $\begin{array}{c}\boldsymbol{T}_{\mathbf{5} \%} \\
{\left[{ }^{\circ} \mathbf{C}\right]}\end{array}$ & $\begin{array}{c}\boldsymbol{T}_{\mathbf{d}} \\
{\left[{ }^{\circ} \mathbf{C}\right]}\end{array}$ \\
\hline Pa12-N & 269 & 418 & 479 \\
\hline PA12-C15 & 164 & 256 & 470 \\
\hline PA12-C30 & 160 & 250 & 470 \\
\hline PA12-C45 & 160 & 244 & 470 \\
\hline PA12-C60 & 159 & 243 & 469 \\
\hline PA12-P15 & 164 & 256 & 483 \\
\hline PA12-P30 & 162 & 239 & 482 \\
\hline PA12-P45 & 165 & 247 & 480 \\
\hline PA12-P60 & 159 & 219 & 479 \\
\hline
\end{tabular}

$T_{1 \%}$ temperature corresponding to a mass loss of $1 \%\left[{ }^{\circ} \mathrm{C}\right]$

$T_{5 \%}$ temperature corresponding to a mass loss of $5 \%\left[{ }^{\circ} \mathrm{C}\right]$

$T_{\mathrm{d}}$ degradation temperature, associated to the maximum mass loss rate $\left[{ }^{\circ} \mathrm{C}\right]$ the PCM degradation step is not proportional to the nominal ParCNT content, since it is nearly constant, being approximately $9 \%$. This is in good agreement with the DSC results and suggests that the majority of the PCM leaked out of the matrix during the production process. On the other hand, the residue at the end of the test is proportional to the ParCNT content. The residue is mostly due to the CNTs, whose degradation in $\mathrm{N}_{2}$ atmosphere can be considered negligible in this case, and thus it can be assumed that, unlike the paraffin, the CNTs do not leave the blends during the production process. This is consistent with the MFI results, since the CNTs are considered as the major responsible for the dramatic increase in viscosity observed for the matrices with ParCNT. Figure 4 shows representative stress-strain curves obtained during quasi-static tensile tests, while the most important mechanical parameters are reported in Table 5. All the considered mechanical properties of the blends are lower than that of PA12-N. For both systems, all the properties have a negative trend with the PCM content, which can be due to the poor 

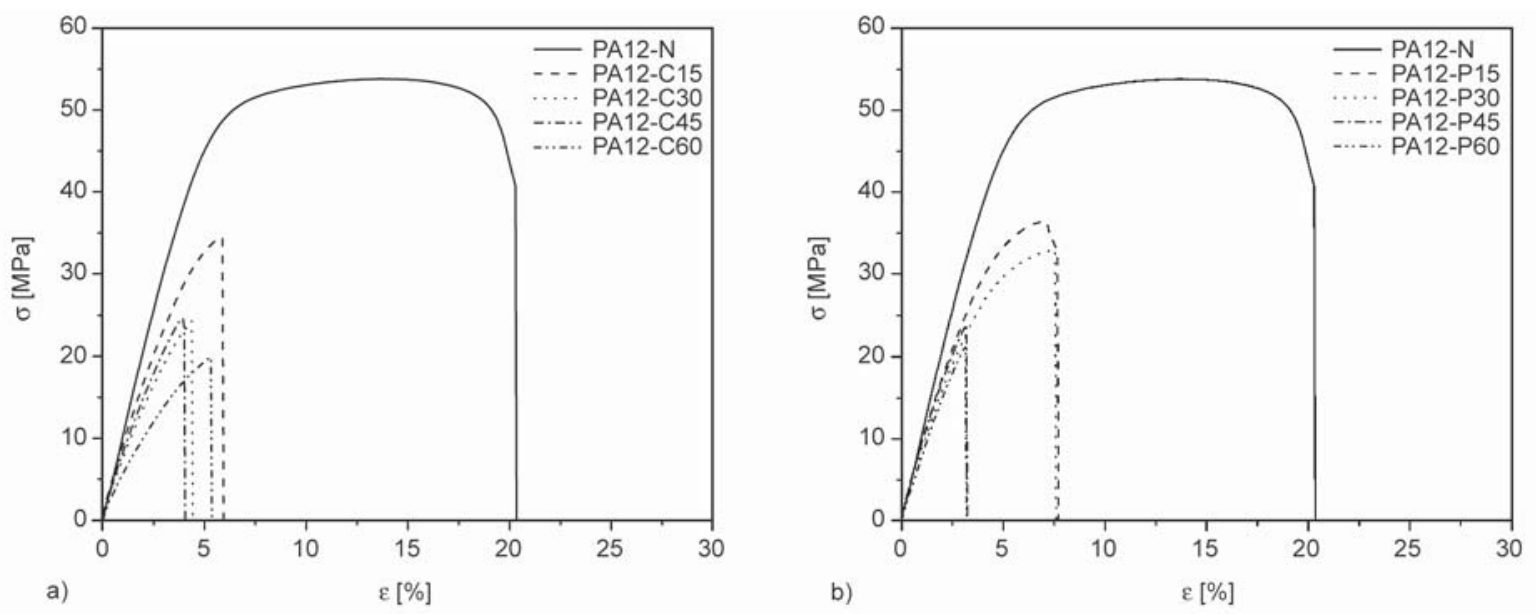

Figure 4. Representative stress-strain curves of the prepared matrices in the quasi static tensile tests. (a) Matrices with capsules; (b) matrices with paraffin and CNTs.

mechanical properties of the PCMs themselves. The only exception is represented by the elastic modulus in the matrices with ParCNT, increasing as the ParCNT content increase, which could be due to the increasing amount of CNTs within the matrix. This conclusion is in good agreement with the results of the thermal characterization and with those of the Vicat tests, reported in Table 5. The values of Vicat softening temperature (VST) of the blends are close to that of the PA12-N, which indicates that the melting of both PCMs does not lead to a remarkable softening of the matrix. For the matrices with ParCNT, the $V S T$ slightly increases with the PCM content, which can be once again due to the presence of CNTs.

The physical, thermal and mechanical characterization of the matrices highlighted that the capsules may be most suitable than ParCNT in combination with the PA12, in the perspective of producing long fiber multifunctional composites, if both the processability and the thermo mechanical properties are considered. However, laminates were produced with both matrix systems as well, at two different PCM fractions (30 and $60 \mathrm{wt} \%$ respect to the matrix), and compared with the laminate without PCM. The results of the characterization are reported hereafter.

\subsection{Characterization of the laminates}

Figure 5 shows the optical microscope images of the polished surface of the produced laminates. Observing the images at lower magnification (Figure 5a-5c, $5 \mathrm{e}, 5 \mathrm{f})$ it can be seen that the fibers in all the laminates are wetted homogeneously and kept the orientation set in the die during the preliminary operation of the hot pressing. The proper fiber wetting can be better appreciated in the high magnification image of GF-C60 (Figure 5d), where also the capsules can be observed in the interlaminar region. The only exception is GF-P60 (Figure 5f), in which the fibers are not properly wetted and the weaving of the fabric seems distorted. A non homogeneous distribution of the matrix across the thickness of the laminate and an incomplete wetting of the fabric can be easily observed, and it was probably due to the high viscosity of the matrix (see MFI results in Section 3.1).

Table 5. Results from quasi static tensile tests and Vicat tests on the prepared matrices

\begin{tabular}{|l|c|c|c|c|c|c|}
\hline \multicolumn{1}{|c|}{ Sample } & $\begin{array}{c}\boldsymbol{E} \\
{[\mathbf{M P a}]}\end{array}$ & $\begin{array}{c}\boldsymbol{\sigma}_{\mathbf{y}} \\
{[\mathbf{M P a}]}\end{array}$ & $\begin{array}{c}\boldsymbol{\varepsilon}_{\mathbf{y}} \\
{[\mathbf{\%}]}\end{array}$ & $\begin{array}{c}\boldsymbol{\sigma}_{\mathbf{B}} \\
{[\mathbf{M P a}]}\end{array}$ & $\begin{array}{c}\boldsymbol{\varepsilon}_{\mathbf{B}} \\
{[\mathbf{\%}]}\end{array}$ & $\begin{array}{c}\boldsymbol{V} \boldsymbol{T} \boldsymbol{} \\
{\left[{ }^{\circ} \mathbf{C}\right]}\end{array}$ \\
\hline PA12-N & $1794 \pm 91$ & $52.5 \pm 1.4$ & $13.4 \pm 1.6$ & $40.3 \pm 1.9$ & $20.0 \pm 1.3$ & 175.3 \\
\hline PA12-C15 & $1340 \pm 73$ & $34.7 \pm 1.2$ & $5.7 \pm 0.2$ & $34.7 \pm 1.2$ & $5.7 \pm 0.2$ & 172.5 \\
\hline PA12-C30 & $1007 \pm 49$ & $24.6 \pm 1.5$ & $5.3 \pm 0.7$ & $24.6 \pm 1.5$ & $5.7 \pm 0.2$ & 173.2 \\
\hline PA12-C45 & $1027 \pm 29$ & $24.8 \pm 4.5$ & $4.2 \pm 1.0$ & $24.6 \pm 1.5$ & $4.2 \pm 1.0$ & 172.5 \\
\hline PA12-C60 & $973 \pm 39$ & $20.0 \pm 2.2$ & $5.6 \pm 0.8$ & $20.0 \pm 2.2$ & $5.6 \pm 0.8$ & 173.2 \\
\hline PA12-P15 & $1316 \pm 67$ & $29.8 \pm 4.6$ & $5.1 \pm 1.4$ & $27.5 \pm 3.4$ & $5.5 \pm 1.6$ & 173.2 \\
\hline PA12-P30 & $1345 \pm 17$ & $32.3 \pm 2.4$ & $6.4 \pm 1.3$ & $31.8 \pm 2.7$ & $6.7 \pm 1.3$ & 174.6 \\
\hline PA12-P45 & $1378 \pm 38$ & $27.6 \pm 2.5$ & $4.2 \pm 0.7$ & $22.7 \pm 6.6$ & $4.2 \pm 0.6$ & 175.7 \\
\hline PA12-P60 & $1529 \pm 55$ & $24.1 \pm 6.5$ & $3.3 \pm 1.3$ & $23.2 \pm 7.3$ & $3.3 \pm 1.2$ & 179.4 \\
\hline
\end{tabular}




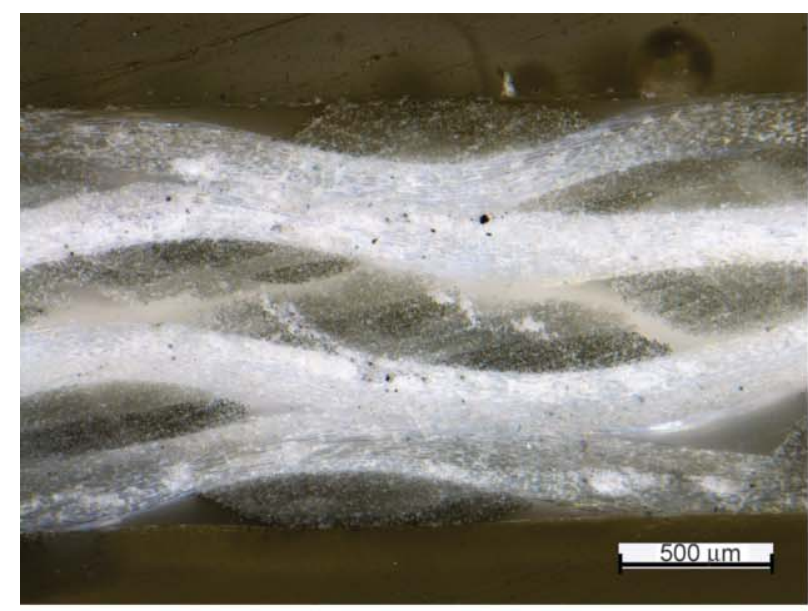

a)

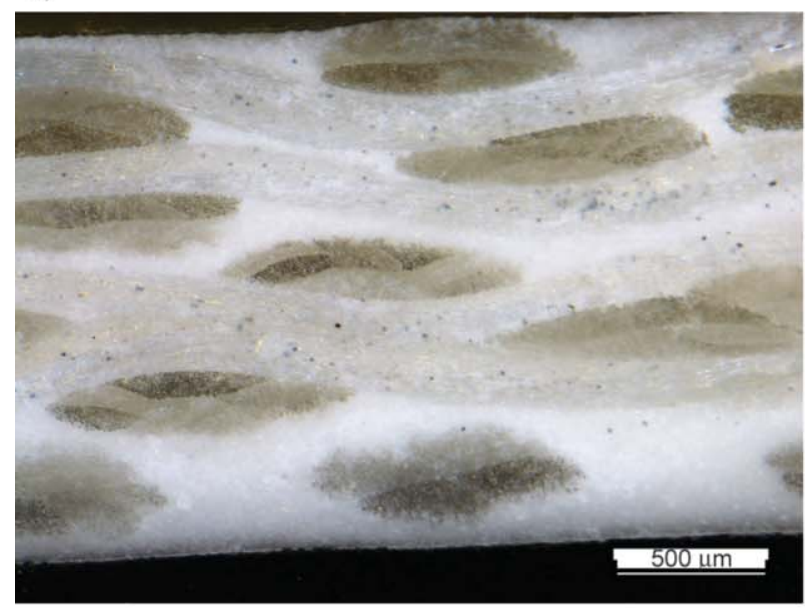

c)

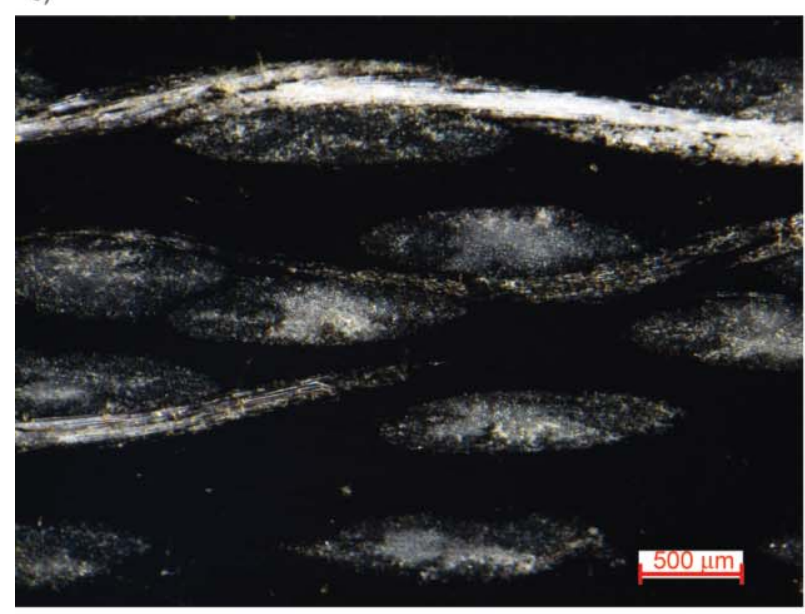

e)

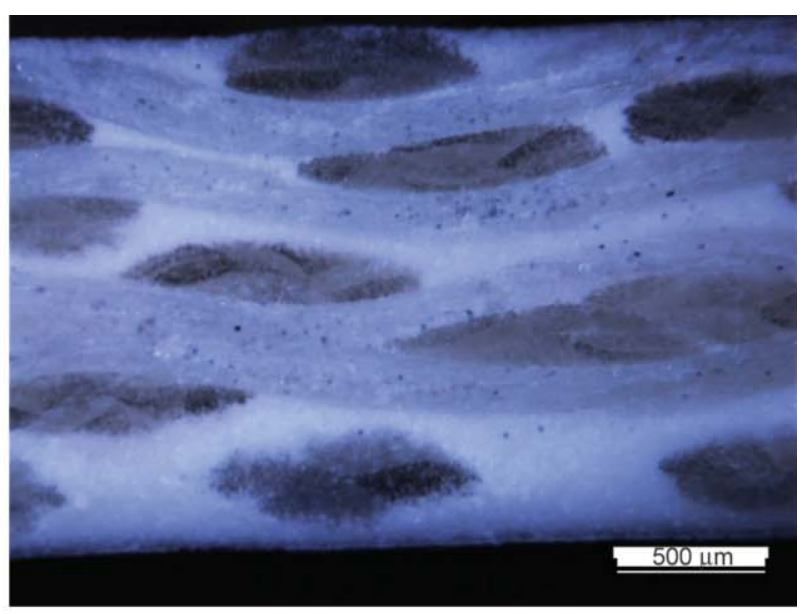

b)

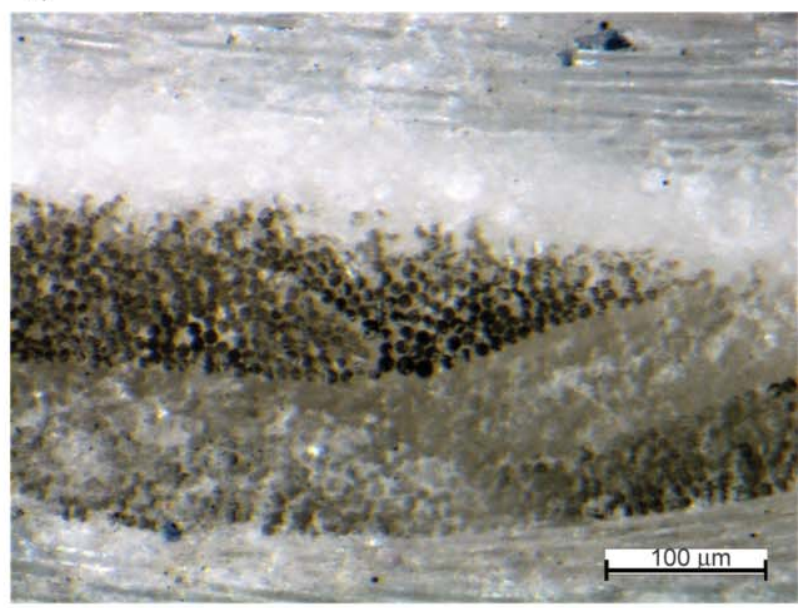

d)

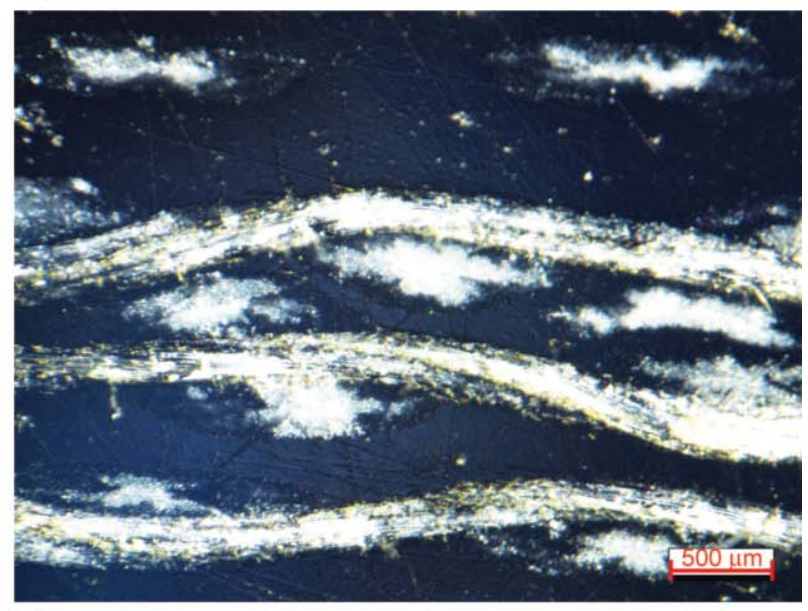

f)

Figure 5. Optical microscope images of the polished surface of the prepared laminates (a) GF-N, 48×; (b) GF-C30, 48×; (c) GF-C60, 48×; (d) GF-C60, 256×; (e) GF-P30, 48×; (f) GF-P60, 48×.

After the production of the laminates, it is important to evaluate the real weight and volume fractions of fibers and matrix, and the volume fraction of voids. This was performed through TGA measurements, which allowed an evaluation of the fiber weight fraction and the calculation of a theoretical density, and through He pycnometry, which led to the measurement of an experimental density and to the calculation of the volume composition. The results of this analysis are reported in Table 6 . The fiber volume fraction is nearly the same for the laminates GF-N, GF-C30, GF-C60 and GF-P30, being around $50-55$ vol\%, and also the volume fraction of voids is similar in these samples (around 2 vol\%). This means that the properties of these laminates can be directly compared. On the other hand, in the GF-P60 laminate the void 
Table 6. Volume fractions of the constituents of the prepared laminates

\begin{tabular}{|l|c|c|c|}
\hline \multicolumn{1}{|c|}{ Sample } & $\begin{array}{c}\boldsymbol{\varphi}_{\mathbf{f}} \\
{[\mathbf{v o l} \% \mathbf{o}}\end{array}$ & $\begin{array}{c}\boldsymbol{\varphi}_{\mathbf{m}} \\
{[\mathbf{v o l} \% \mathbf{l}}\end{array}$ & $\begin{array}{c}\boldsymbol{\varphi}_{\mathbf{v}} \\
{[\mathbf{v o l} \% \mathbf{~}]}\end{array}$ \\
\hline GF-N & 53.4 & 44.5 & 2.1 \\
\hline GF-C30 & 55.5 & 42.2 & 2.3 \\
\hline GF-C60 & 53.2 & 44.3 & 2.5 \\
\hline GF-P30 & 50.5 & 47.7 & 1.8 \\
\hline GF-P60 & 32.4 & 57.8 & 9.8 \\
\hline
\end{tabular}

$\varphi_{\mathrm{f}} \quad$ fiber volume fraction $[\mathrm{vol} \%]$

$\varphi_{\mathrm{m}}$ matrix volume fraction [ $\left.\mathrm{vol} \%\right]$

$\varphi_{\mathrm{v}} \quad$ voids volume fraction [vol\%]

volume fraction is considerably higher (9.8 vol\%), in accordance with the optical microscope results, and the fiber volume content is noticeably lower (i.e. $32.7 \mathrm{vol} \%$ ). This does not allow a proper comparison of this sample with the others.

Figure 6 shows the DSC thermograms relative to the first heating and the cooling scan of the prepared laminates, respectively. In Figure 6b, the temperature

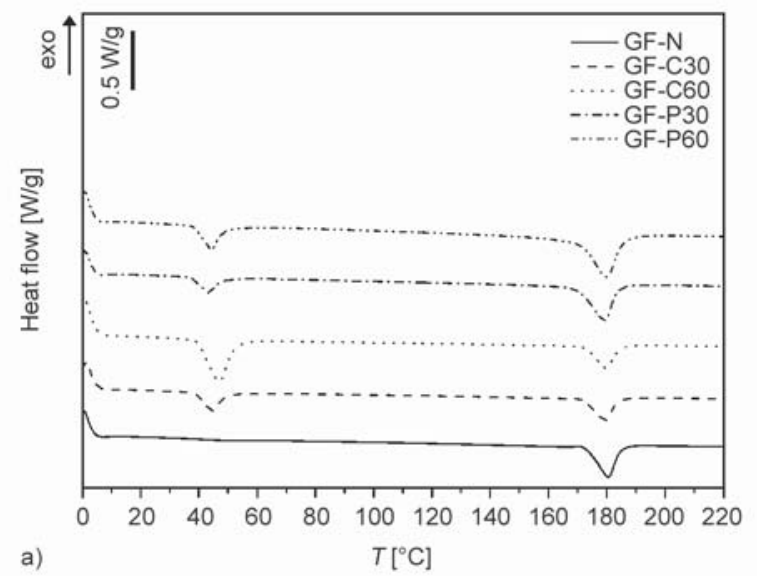

axis decreases from 220 to $0^{\circ} \mathrm{C}$ to better present the cooling scan results. The most important DSC results are summarized in Table 7. As for the matrices (see Section 3.1), the data of the second heating scan are not reported for the sake of brevity, as no important differences were detected between the first and the second heating scan. The aim of this analysis was to investigate if the additional hot pressing thermal cycle required to produce laminates further deteriorates the PCM energy storage/release capability. As observed for the matrices, in the heating scan (Figure 6a) two endothermic peaks are present, which are associated to the melting of the PCM and of the PA12, respectively. As reported in Table 7, the composite with the best thermal performance is GF-C60, developing a melting enthalpy of $17.1 \mathrm{~J} / \mathrm{g}\left(\Delta H_{\mathrm{m}}^{\mathrm{rel}}=\right.$ $53 \%$ ). However, the values of relative enthalpies are lower than those of the corresponding matrices, which indicates that the lamination process further decreases the thermal energy storage/release capability,

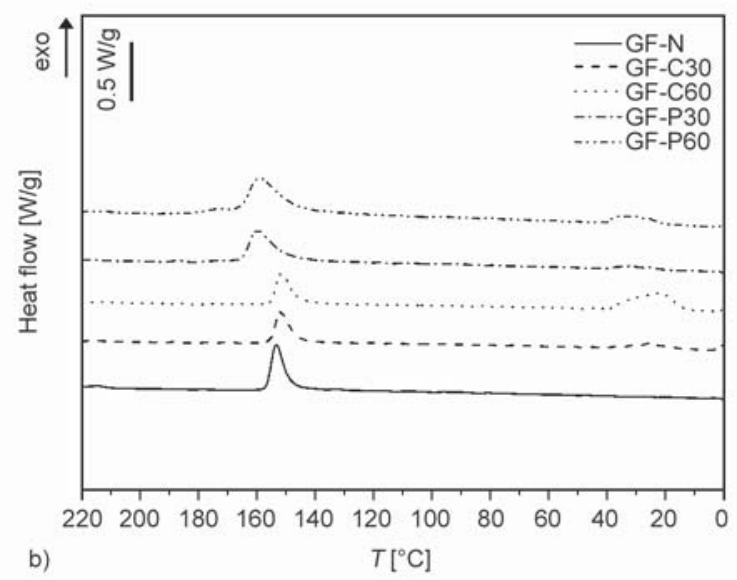

b)

Figure 6. DCS thermograms of the prepared laminates. (a) first heating scan; (b) cooling scan.

Table 7. Results of the DSC tests on the prepared laminates

\begin{tabular}{|l|c|c|c|c|c|c|c|c|c|}
\hline \multicolumn{1}{|c}{ Sample } & $\begin{array}{c}\boldsymbol{T}_{\mathbf{m}} \\
{\left[{ }^{\circ} \mathbf{C}\right]}\end{array}$ & $\begin{array}{c}\Delta \boldsymbol{H}_{\mathbf{m}} \\
{[\mathbf{J} / \mathbf{g}]}\end{array}$ & $\begin{array}{c}\Delta \boldsymbol{H}_{\mathbf{m}}^{\text {rel }} \\
{\left[\mathbf{\%}^{\text {rel }}\right.}\end{array}$ & $\begin{array}{c}\boldsymbol{T}_{\mathbf{m}}^{\mathbf{P A}} \\
{\left[{ }^{\circ} \mathbf{C}\right]}\end{array}$ & $\begin{array}{c}\Delta \boldsymbol{H}_{\mathbf{m}}^{\mathbf{P A}} \\
{[\mathbf{J} / \mathbf{g}]}\end{array}$ & $\begin{array}{c}\boldsymbol{T}_{\mathbf{c}} \\
{\left[{ }^{\circ} \mathbf{C}\right]}\end{array}$ & $\begin{array}{c}\Delta \boldsymbol{H}_{\mathbf{c}} \\
{[\mathbf{J} / \mathbf{g}]}\end{array}$ & $\begin{array}{c}\boldsymbol{T}_{\mathbf{c}}^{\mathbf{P A}} \\
{\left[{ }^{\circ} \mathbf{C}\right]}\end{array}$ & $\begin{array}{c}\Delta \boldsymbol{H}_{\mathbf{c}} \mathbf{P A} \\
{[\mathbf{J} / \mathbf{g}]}\end{array}$ \\
\hline GF-N & - & - & - & 179.9 & 11.5 & - & - & 154.2 & 11.4 \\
\hline GF-C30 & 43.9 & 6.5 & 44.2 & 178.8 & 8.7 & 25.2 & 3.1 & 152.4 & 8.3 \\
\hline GF-C60 & 46.3 & 17.1 & 52.7 & 178.9 & 8.5 & 23.2 & 13.8 & 152.4 & 8.0 \\
\hline GF-P30 & 43.0 & 5.3 & 31.9 & 178.5 & 16.2 & 39.7 & 2.0 & 160.3 & 16.1 \\
\hline GF-P60 & 43.5 & 8.4 & 15.8 & 178.7 & 21.0 & 31.3 & 5.6 & 160.1 & 21.0 \\
\hline
\end{tabular}

$T_{\mathrm{m}} \quad$ melting temperature of the $\mathrm{PCM}\left[{ }^{\circ} \mathrm{C}\right]$

$\Delta H_{\mathrm{m}} \quad$ PCM melting enthalpy [J/g]

$\Delta H_{\mathrm{m}}^{\text {rel }}$ relative PCM melting enthalpy [\%]

$T_{\mathrm{m}}^{\mathrm{PA}}$ melting temperature of PA12 $\left[{ }^{\circ} \mathrm{C}\right]$

$\Delta H_{\mathrm{m}}^{\mathrm{PA}}$ melting enthalpy of PA12 [J/g]

$T_{\mathrm{c}} \quad$ crystallization temperature of the PCM $\left[{ }^{\circ} \mathrm{C}\right]$

$\Delta H_{\mathrm{c}} \quad$ PCM crystallization enthalpy [J/g]

$T_{\mathrm{c}}^{\mathrm{PA}} \quad$ crystallization temperature of PA $12\left[{ }^{\circ} \mathrm{C}\right]$

$\Delta H_{\mathrm{c}}^{\mathrm{PA}}$ crystallization enthalpy of PA12 [J/g] 
causing additional breaking of capsules and degradation of paraffin. Further efforts will be made in the future to prevent microcapsule damage and improve the thermal energy storage/release properties of the prepared composites. The composites with ParCNT present a much greater decrease of relative melting enthalpy respect to the matrices, and the values of $\Delta H_{\mathrm{m}}^{\text {rel }}$ are not even proportional to the ParCNT fraction. This suggests that, during the process, the ParCNT degrades more than the microencapsulated PCM, which is in good agreement with the TGA results (see Figure 3). This suggests that, considering the processing conditions, the microcapsules can be more easily incorporated in a glass fiber/PA12 laminate. As already observed in the matrices (see Table 3 ) the crystallization temperature of PA12 matrix is increased of about $5^{\circ} \mathrm{C}$ in the ParCNT based laminates, because of the nucleating effect played by CNTs in the matrix.

Finally, the mechanical properties of the laminates were evaluated through tensile tests and short beam shear tests. Figure 7 shows representative stress-strain curves of the tensile tests on the prepared laminates, while the most important results are summarized in Table 8. The stress at break decreases upon PCM addition, and this effect is more evident for the laminates with ParCNT, in which also the elastic modulus decreases compared to the laminate without PCM (GF-N). Conversely, the elastic moduli of both laminates with capsules are not significantly different from that of GF-N, indicating that in these laminates the stiffness is determined essentially by the elastic properties of the reinforcement, and the matrix properly fulfils the role of transferring the load to the

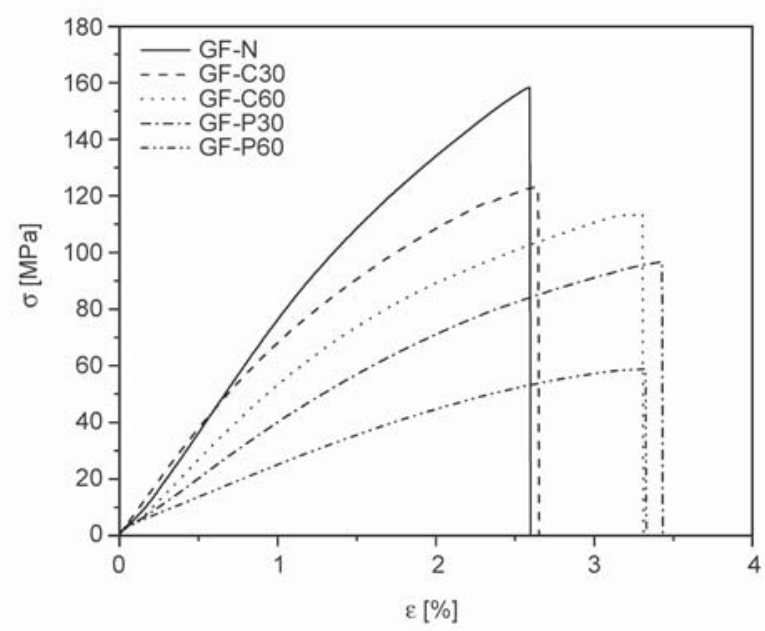

Figure 7. Representative stress-strain curves obtained during quasi static tensile tests on the prepared laminates
Table 8. Results of the quasi static tensile tests and short beam shear tests on the prepared laminates

\begin{tabular}{|l|c|c|c|c|}
\hline \multicolumn{1}{|c|}{ Sample } & $\begin{array}{c}\boldsymbol{E} \\
{[\mathbf{G P a}]}\end{array}$ & $\begin{array}{c}\boldsymbol{\sigma}_{\mathbf{B}} \\
{[\mathbf{M P a}]}\end{array}$ & $\begin{array}{c}\boldsymbol{\varepsilon}_{\mathbf{B}} \\
{[\mathbf{\%}]}\end{array}$ & $\begin{array}{c}\boldsymbol{I L S S} \\
{[\mathbf{M P a}]}\end{array}$ \\
\hline GF-N & $13.1 \pm 0.3$ & $160 \pm 29$ & $2.7 \pm 0.3$ & $11.2 \pm 1.7$ \\
\hline GF-C30 & $12.7 \pm 0.9$ & $124 \pm 18$ & $3.0 \pm 0.4$ & $9.8 \pm 1.7$ \\
\hline GF-C60 & $13.3 \pm 0.7$ & $114 \pm 10$ & $3.0 \pm 0.7$ & $9.4 \pm 2.1$ \\
\hline GF-P30 & $9.9 \pm 0.4$ & $92 \pm 9$ & $3.5 \pm 0.1$ & $6.7 \pm 0.3$ \\
\hline GF-P60 & $6.5 \pm 0.1$ & $56 \pm 15$ & $3.5 \pm 1.1$ & $5.5 \pm 1.8$ \\
\hline
\end{tabular}

fibers. Additionally, also the strain at break values are not negatively affected by the PCM addition, and thus it can be concluded that the mechanical properties of the resulting laminates are only marginally influenced by microcapsules addition within the materials, while a sensible drop of the mechanical performances can be observed with ParCNT addition.

As mentioned before, the interlaminar properties of the laminates were investigated through a short beam shear test. Values of interlaminar shear strength (ILSS) are reported in Table 8. Once again, if the standard deviations are considered, the laminates with capsules do not show a significantly different performance with respect to the laminate without PCM (GF-N), while the interlaminar properties of the laminates with ParCNT sharply decrease, proportionally to the PCM concentration. This can be attributed to the poor adhesion, as a result of the high viscosity of the matrices involved, and to the lower mechanical properties of the matrices with ParCNT.

\section{Conclusions}

In this work, glass fiber reinforced thermoplastic composite laminates with thermal energy storage/release capability were prepared by combining a PA12 matrix with two different paraffin based PCMs (microcapsules and ParCNT), and the physical properties of the resulting materials were thoroughly characterized.

MFI tests on the matrices showed that the fluidity of the PA12 decreased with an increase of the PCM content. For the system with ParCNT this decrease was more evident than for the systems with microcapsules, which suggests that the latter could be processed more easily. DSC analysis revealed that, for the systems with capsules, the melting enthalpy increased with the PCM content. These systems developed a melting enthalpy which was approximately $70 \%$ of the expected one, and the enthalpy loss was attributed to the breaking of some capsules and the 
leakage/degradation of the PCM. The drop of the melting/crystallization enthalpy was heavier for the systems with ParCNT, due to a greater paraffin degradation and leakage during the production process, as a consequence of the lower thermal stability of ParCNT compared to the capsules. For both systems, the Vicat softening temperature was almost not affected by the presence of the PCMs, nor did the PCM melting determine a loss in the dimensional stability. Quasi static tensile tests showed that the mechanical properties of the blends were lower than those of the neat PA12, probably because of the lower mechanical properties of the PCM and/or the not perfect adhesion with PA12. Only a slight increase of elastic modulus at elevated ParCNT concentrations was observed, due to the considerable percentage of CNTs, but the modulus was always lower than that of the neat PA12.

The subsequent characterization of the laminates highlighted that the fiber and void volume fractions were comparable for all the laminates except for that with the higher amount of ParCNT, where the high viscosity of the matrix led to a lower fiber volume fraction and a higher void content. DSC tests showed that the relative enthalpy values of the laminates were lower than those of the corresponding matrices, which indicates that the lamination process probably determined a further breaking of capsules and degradation of paraffin. The mechanical properties of the laminates were only slightly impaired by microcapsules addition, while a more sensible drop of the elastic modulus, of the stress at break and of the interlaminar shear strength could be observed in the systems with ParCNT.

The results of this work indicated that the microencapsulated PCM was more suitable to produce structural TES composites in combination with a PA12 matrix and glass fibers, since it showed a greater thermal stability and did not impair the mechanical properties of the laminates. The performed experiments are a good starting point for the design and fabrication of thermoplastic composites with TES capability, and further efforts will be made to improve the processing conditions and limit damage of microcapsules, thus increasing the thermal energy storage/release properties of the prepared composites.

\section{Acknowledgements}

Mr. Tiziano Meneghini is gratefully acknowledged for his support to the experimental activities.

\section{References}

[1] Pielichowska K., Pielichowski K.: Phase change materials for thermal energy storage. Progress in Materials Science, 65, 67-123 (2014).

https://doi.org/10.1016/j.pmatsci.2014.03.005

[2] Kalaiselvam S., Parameshwaran R.: Latent thermal energy storage. in 'Thermal energy storage technologies for sustainability' (eds.: Kalaiselvam S., Parameshwaran R.) Elsevier, Amsterdam, 83-126 (2014). https://doi.org/10.1016/B978-0-12-417291-3.00005-0

[3] Kenisarin M. M., Kenisarina K. M.: Form-stable phase change materials for thermal energy storage. Renewable and Sustainable Energy Reviews, 16, 1999-2040 (2012).

https://doi.org/10.1016/j.rser.2012.01.015

[4] Wang Z., Qiu F., Yang W., Zhao X.: Applications of solar water heating system with phase change material. Renewable and Sustainable Energy Reviews, 52, 645652 (2015).

https://doi.org/10.1016/j.rser.2015.07.184

[5] Farid M. M., Khudhair A. M., Razack S. A. K., Al-Hallaj S.: A review on phase change energy storage: Materials and applications. Energy Conversion and Management, 45, 1597-1615 (2004).

https://doi.org/10.1016/j.enconman.2003.09.015

[6] Kuznik F., David D., Johannes K., Roux J-J.: A review on phase change materials integrated in building walls. Renewable and Sustainable Energy Reviews, 15, 379391 (2011).

https://doi.org/10.1016/j.rser.2010.08.019

[7] Khudhair A. M., Farid M. M.: A review on energy conservation in building applications with thermal storage by latent heat using phase change materials. Energy Conversion and Management, 45, 263-275 (2004). https://doi.org/10.1016/S0196-8904(03)00131-6

[8] Ostry M., Charvat P.: Materials for advanced heat storage in buildings. Procedia Engineering, 57, 837-843 (2013).

https://doi.org/10.1016/j.proeng.2013.04.106

[9] Hasnain S. M.: Review on sustainable thermal energy storage technologies, Part I: Heat storage materials and techniques. Energy Conversion and Management, 39, 1127-1138 (1998). https://doi.org/10.1016/S0196-8904(98)00025-9

[10] Trigui A., Karkri M., Boudaya C., Candau Y., Ibos L., Fois M.: Experimental investigation of a composite phase change material: Thermal-energy storage and release. Journal of Composite Materials, 48, 49-62 (2014). https://doi.org/10.1177/0021998312468185

[11] Himran S., Suwono A., Mansoori G. A.: Characterization of alkanes and paraffin waxes for application as phase change energy storage medium. Energy Sources, 16, 117-128 (1994). https://doi.org/10.1080/00908319408909065 
[12] Jeong S-G., Kim S., Huh W.: Preparation of epoxy resin using n-hexadecane based shape stabilized PCM for applying wood-based flooring. Journal of Adhesion Science and Technology, 28, 711-721 (2014).

https://doi.org/10.1080/01694243.2013.865331

[13] Akgün M., Aydın O., Kaygusuz K.: Experimental study on melting/solidification characteristics of a paraffin as PCM. Energy Conversion and Management, 48, 669678 (2007).

https://doi.org/10.1016/j.enconman.2006.05.014

[14] Sharma R. K., Ganesan P., Tyagi V. V., Metselaar H. S. C., Sandaran S. C.: Developments in organic solid-liquid phase change materials and their applications in thermal energy storage. Energy Conversion and Management, 95, 193-228 (2015).

https://doi.org/10.1016/j.enconman.2015.01.084

[15] Khadiran T., Hussein M. Z., Zainal Z., Rusli R.: Encapsulation techniques for organic phase change materials as thermal energy storage medium: A review. Solar Energy Materials and Solar Cells, 143, 78-98 (2015). https://doi.org/10.1016/j.solmat.2015.06.039

[16] Onder E., Sarier N., Cimen E.: Encapsulation of phase change materials by complex coacervation to improve thermal performances of woven fabrics. Thermochimica Acta, 467, 63-72 (2008).

https://doi.org/10.1016/j.tca.2007.11.007

[17] Su J-F., Wang X-Y., Wang S-B., Zhao Y-H., Zhu K-Y., Yuan X-Y.: Interface stability behaviors of methanolmelamine-formaldehyde shell microPCMs/epoxy matrix composites. Polymer Composites, 32, 810-820 (2011).

https://doi.org/10.1002/pc.21102

[18] Sobolciak P., Karkri M., Al-Maaded M. A., Krupa I.: Thermal characterization of phase change materials based on linear low-density polyethylene, paraffin wax and expanded graphite. Renewable Energy, 88, 372 382 (2016).

https://doi.org/10.1016/j.renene.2015.11.056

[19] Mu M., Basheer P. A. M., Sha W., Bai Y., McNally T.: Shape stabilised phase change materials based on a high melt viscosity HDPE and paraffin waxes. Applied Energy, 162, 68-82 (2016).

https://doi.org/10.1016/j.apenergy.2015.10.030

[20] Luyt A. S., Krupa I.: Phase change materials formed by UV curable epoxy matrix and Fischer-Tropsch paraffin wax. Energy Conversion and Management, 50, 57-61 (2009).

https://doi.org/10.1016/j.enconman.2008.08.026

[21] Sari A., Akcay M., Soylak M., Onal A.: Polymer-stearic acid blends as form-stable phase change material for thermal energy storage. Journal of Scientific and Industrial Research, 64, 991-996 (2005).

[22] Wirtz R., Fuchs A., Narla V., Shen Y., Zhao T., Jiang Y.: A multi-functional graphite/epoxy-based thermal energy storage composite for temperature control of sensors and electronics. in ' $41^{\text {st }}$ Aerospace Sciences Meeting and Exhibit, Aerospace Sciences Meetings, Reno, USA' 0513/1-0513/10 (2003).
[23] Zhang P., Hu Y., Song L., Ni J., Xing W., Wang J.: Effect of expanded graphite on properties of high-density polyethylene/paraffin composite with intumescent flame retardant as a shape-stabilized phase change material. Solar Energy Materials and Solar Cells, 94, 360365 (2010).

https://doi.org/10.1016/j.solmat.2009.10.014

[24] Sari A., Soylak M.: Equilibrium and thermodynamic studies of stearic acid adsorption on Celtek clay. Journal of the Serbian Chemical Society, 72, 485-494 (2007). https://doi.org/10.2298/jsc0705485s

[25] Dorigato A., Canclini P., Unterberger S. H., Pegoretti A.: Phase changing nanocomposites for low temperature thermal energy storage and release. Express Polymer Letters, 11, 738-752 (2017). https://doi.org/10.3144/expresspolymlett.2017.71

[26] Mehrali M., Latibari S. T., Mehrali M., Mahlia T. M. I., Metselaar H. S. C.: Effect of carbon nanospheres on shape stabilization and thermal behavior of phase change materials for thermal energy storage. Energy Conversion and Management, 88, 206-213 (2014). https://doi.org/10.1016/j.enconman.2014.08.014

[27] Huang X., Lin Y., Alva G., Fang G. Y.: Thermal properties and thermal conductivity enhancement of composite phase change materials using myristyl alcohol/metal foam for solar thermal storage. Solar Energy Materials and Solar Cells, 170, 68-76 (2017). https://doi.org/10.1016/j.solmat.2017.05.059

[28] Chen Y., Luo W., Wang J., Huang J.: Enhanced thermal conductivity and durability of a paraffin wax nanocomposite based on carbon-coated aluminum nanoparticles. Journal of Physical Chemistry C, 121, 12603-12609 (2017).

https://doi.org/10.1021/acs.jpcc.7b02651

[29] Dorigato A., Ciampolillo M. V., Cataldi A., Bersani M., Pegoretti A.: Polyethylene wax/EPDM blends as shapestabilized phase change materials for thermal energy storage. Rubber Chemistry and Technology, 90, 575584 (2017).

https://doi.org/10.5254/rct.82.83719

[30] Cui Y., Xie J., Liu J., Pan S.: Review of phase change materials integrated in building walls for energy saving. Procedia Engineering, 121, 763-770 (2015). https://doi.org/10.1016/j.proeng.2015.09.027

[31] Ibáñez M., Cabeza L. F., Solé C., Roca J., Nogués M.: Modelization of a water tank including a PCM module. Applied Thermal Engineering, 26, 1328-1333 (2006). https://doi.org/10.1016/j.applthermaleng.2005.10.022

[32] Kürklü A., Özmerzi A., Bilgin S.: Thermal performance of a water-phase change material solar collector. Renewable Energy, 26, 391-399 (2002). https://doi.org/10.1016/S0960-1481(01)00130-6

[33] Shin Y., Yoo D-I., Son K.: Development of thermoregulating textile materials with microencapsulated phase change materials (PCM). II. Preparation and application of PCM microcapsules. Journal of Applied Polymer Science, 96, 2005-2010 (2005). https://doi.org/10.1002/app.21438 
[34] Salonitis K., Pandremenos J., Paralikas J., Chryssolouris G.: Multifunctional materials: Engineering applications and processing challenges. International Journal of Advanced Manufacturing Technology, 49, 803 826 (2010).

https://doi.org/10.1007/s00170-009-2428-6

[35] Gibson R. F.: A review of recent research on mechanics of multifunctional composite materials and structures. Composite Structures, 92, 2793-2810 (2010). https://doi.org/10.1016/j.compstruct.2010.05.003

[36] Carlson T.: Multifunctional composite materials. Design, manufacture and experimental characterization. $\mathrm{PhD}$ thesis, Luleå University of Technology (2013).

[37] Friedrich K.: Routes for achieving multifunctionality in reinforced polymers and composite structures. in 'Multifunctionality of polymer composites' (eds.: Friedrich K., Breuer U.) Elsevier, Oxford, 3-41 (2015). https://doi.org/10.1016/B978-0-323-26434-1.00001-5

[38] Christodoulou L., Venables J. D.: Multifunctional material systems: The first generation. Journal of the Minerals, 55, 39-45 (2003).

https://doi.org/10.1007/s11837-003-0008-Z

[39] Wang X-Y., Su J-F., Wang S-B., Zhao Y-H.: The effect of interface debonding behaviors on the mechanical properties of microPCMs/epoxy composites. Polymer Composites, 32, 1439-1450 (2011).

https://doi.org/10.1002/pc.21174

[40] Su J-F., Zhao Y-H., Wang X-Y., Dong H., Wang S-B.: Effect of interface debonding on the thermal conductivity of microencapsulated-paraffin filled epoxy matrix composites. Composites Part A: Applied Science and Manufacturing, 43, 325-332 (2012).

https://doi.org/10.1016/j.compositesa.2011.12.003

[41] Kastiukas G., Zhou X. M., Castro-Gomes J.: Development and optimisation of phase change material-impregnated lightweight aggregates for geopolymer composites made from aluminosilicate rich mud and milled glass powder. Construction and Building Materials, 110, 201-210 (2016).

https://doi.org/10.1016/j.conbuildmat.2016.02.029

[42] Zhang P., Xiao X., Ma Z. W.: A review of the composite phase change materials: Fabrication, characterization, mathematical modeling and application to performance enhancement. Applied Energy, 165, 472-510 (2016). https://doi.org/10.1016/j.apenergy.2015.12.043

[43] Silverman E.: Multifunctional carbon foam development for spacecraft applications. Sampe Journal, 41, 19-23 (2005).

[44] Ozaki T., Takeya H., Kume M., Sekine K.: Multifunctional composite structures for space satellites. Sampe Journal, 44, 6-11 (2008).

[45] Yoo S., Kandare E., Shanks R., Al-Maadeed M. A., Afaghi Khatibi A.: Thermophysical properties of multifunctional glass fibre reinforced polymer composites incorporating phase change materials. Thermochimica Acta, 642, 25-31 (2016).

https://doi.org/10.1016/j.tca.2016.09.003
[46] Yoo S., Kandare E., Shanks R., Khatibi A. A.: Viscoelastic characterization of multifunctional composites incorporated with microencapsulated phase change materials. Materials Today, 4, 5239-5247 (2017).

https://doi.org/10.1016/j.matpr.2017.05.033

[47] Fredi G., Dorigato A., Fambri L., Pegoretti A.: Wax confinement with carbon nanotubes for phase changing epoxy blends. Polymers, 9, 405-420 (2017). https://doi.org/10.3390/polym9090405

[48] Mallick P. K.: Fiber reinforced composites. Materials, manufacturing, and design. CRC Press, Boca Raton (2008).

[49] Biron M.: Thermoplastics and thermoplastic composites. Elsevier, Amsterdam (2013).

[50] Zhong W. H., Maguire R. G., Sangari S. S., Wu P. H.: Major trends in polymeric composites technology. in 'Composite materials research progress' (ed.: Durand L. P.) Nova, New York, 109-128 (2008).

[51] Unterweger C., Brüggemann O., Fürst C.: Synthetic fibers and thermoplastic short-fiber-reinforced polymers: Properties and characterization. Polymer Composites, 35, 227-236 (2014).

https://doi.org/10.1002/pc.22654

[52] Meng Q., Gu Y., Luo L., Wang S., Li M., Zhang Z.: Annealing effect on crystalline structure and mechanical properties in long glass fiber reinforced polyamide- 66 . Journal of Applied Polymer Science, 134, 44832/144832/10 (2017)

https://doi.org/10.1002/app.44832

[53] Dorigato A., Fambri L.: Effect of aramid regenerated fibers on thermo-mechanical behaviour of polyamide 12 composites. Journal of Reinforced Plastics and Composites, 32, 1243-1256 (2013). https://doi.org/10.1177/0731684413486528

[54] Alexandre B., Langevin D., Médéric P., Aubry T., Couderc H., Nguyen Q. T., Saiter A., Marais S.: Water barrier properties of polyamide 12/montmorillonite nanocomposite membranes: Structure and volume fraction effects. Journal of Membrane Science, 328, 186204 (2009).

https://doi.org/10.1016/j.memsci.2008.12.004

[55] Hasook A., Muramatsu H., Tanoue S., Iemoto Y., Unryu T.: Preparation of nanocomposites by melt compounding polylactic acid/polyamide 12/organoclay at different screw rotating speeds using a twin screw extruder. Polymer Composites, 29, 1-8 (2008).

https://doi.org/10.1002/pc.20336

[56] Kim S. S., Shin M. W., Jang H.: Tribological properties of short glass fiber reinforced polyamide 12 sliding on medium carbon steel. Wear, 274, 34-42 (2012). https://doi.org/10.1016/j.wear.2011.08.009

[57] Inceoglu F., Ville J., Ghamri N., Pradel J. L., Durin A., Valette R., Vergnes B.: Correlation between processing conditions and fiber breakage during compounding of glass fiber-reinforced polyamide. Polymer Composites, 32, 1842-1850 (2011). https://doi.org/10.1002/pc.21217 
[58] Shin B-S., Jeun J. P., Kim H-B., Kang P-H.: Thermal behavior and abrasion properties of glass fiber reinforced nylon 12 crosslinked by electron beam irradiation. Polymer-Korea, 35, 30-34 (2011).

[59] Czigány T., Karger-Kocsis J.: A comparison of the mechanical behaviour of weft-knitted glass and carbon fiber fabric-reinforced polyamide-12 composites produced with commingled staple yarns. Polymers and Polymer Composites, 9, 491-497 (2001).

[60] Mochane M. J., Luyt A. S.: Preparation and properties of polystyrene encapsulated paraffin wax as possible phase change material in a polypropylene matrix. Thermochimica Acta, 544, 63-70 (2012).

https://doi.org/10.1016/j.tca.2012.06.017
[61] Krupa I., Nógellová Z., Špitalský Z., Janigová I., Boh B., Sumiga B., Kleinová A., Karkri M., Al Maadeed M. A.: Phase change materials based on high-density polyethylene filled with microencapsulated paraffin wax. Energy Conversion and Management, 87, 400-409 (2014).

https://doi.org/10.1016/j.enconman.2014.06.061

[62] Dorigato A., Brugnara M., Giacomelli G., Fambri L., Pegoretti A.: Thermal and mechanical behavior of innovative melt-blown fabrics based on polyamide nanocomposites. Journal of Industrial Textiles, 45, 1504-1515 (2016). https://doi.org/10.1177/1528083714564633 